\title{
Adipose-tissue-derived Stem Cells Enhance the Healing of Ischemic Colonic Anastomoses: An Experimental Study in Rats
}

\author{
Jong Han Yoo ${ }^{1}$, Jae Ho Shin ${ }^{1}$, Min Sung An ${ }^{1}$, Tae Kwun Ha ${ }^{1}$, Kwang Hee Kim ${ }^{1}$, Ki Beom Bae ${ }^{1,2}$, \\ Tae Hyeon Kim ${ }^{1}$, Chang Soo Choi ${ }^{1}$, Kwan Hee Hong ${ }^{1}$, Jeong Kim ${ }^{3}$, Soo Jin Jung ${ }^{3}$, Sun Hee Kim², \\ Kuk Hwan Rho ${ }^{2}$, Jong Tae Kim², Young Il Yang ${ }^{2,3}$ \\ ${ }^{1}$ Department of Surgery, Busan Paik Hospital, ${ }^{2}$ Paik Institute for Clinical Research, ${ }^{3}$ Department of Pathology, Busan Paik Hospital, \\ Inje University College of Medicine, Busan, Korea
}

Purpose: This experimental study verified the effect of adipose-tissue-derived stem cells (ASCs) on the healing of ischemic colonic anastomoses in rats.

Methods: ASCs were isolated from the subcutaneous fat tissue of rats and identified as mesenchymal stem cells by identification of different potentials. An animal model of colonic ischemic anastomosis was induced by modifying Nagahata's method. Sixty male Sprague-Dawley rats ( 10 -week-old, $370 \pm 50 \mathrm{~g}$ ) were divided into two groups ( $\mathrm{n}=30$ each): a control group in which the anastomosis was sutured in a single layer with 6-0 polypropylene without any treatment and an ASCtreated group (ASC group) in which the anastomosis was sutured as in the control group, but then ASCs were locally transplanted into the bowel wall around the anastomosis. The rats were sacrificed on postoperative day 7 . Healing of the anastomoses was assessed by measuring loss of body weight, wound infection, anastomotic leakage, mortality, adhesion formation, ileus, anastomotic stricture, anastomotic bursting pressure, histopathological features, and microvascular density. Results: No differences in wound infection, anastomotic leakage, or mortality between the two groups were observed. The ASC group had significantly more favorable anastomotic healing, including less body weight lost, less ileus, and fewer ulcers and strictures, than the control group. ASCs augmented bursting pressure and collagen deposition. The histopathological features were significantly more favorable in the ASC group, and microvascular density was significantly higher than it was in the control group.

Conclusion: Locally-transplanted ASCs enhanced healing of ischemic colonic anastomoses by increasing angiogenesis. ASCs could be a novel strategy for accelerating healing of colonic ischemic risk anastomoses.

Keywords: Colonic anastomosis; Ischemia; Anastomotic healing; Adipose-tissue-derived stem cell; Angiogenesis

Received: March 5, 2012 - Accepted: June 13, 2012

Correspondence to: Ki Beom Bae, M.D.

Department of Surgery, Busan Paik Hospital, Inje University College of

Medicine, 75 Bokji-ro, Busanjin-gu, Busan 614-735, Korea

Tel: +82-51-890-6075, Fax: +82-51-898-9427

E-mail:bkbsur@yahoo.co.kr

This study was orally presented at the Colorectal Division of the 2011 Korean Surgical Society Annual Autumn Congress.

(c) 2012 The Korean Society of Coloproctology

This is an open-access article distributed under the terms of the Creative Commons Attribution NonCommercial License (http://creativecommons.org/licenses/by-nc/3.0) which permits unrestricted noncommercial use, distribution, and reproduction in any medium, provided the original work is properly cited.

\section{INTRODUCTION}

Anastomotic dehiscence is one of the most serious complications of colorectal surgery. Breakdown of an anastomosis results in increased morbidity and mortality and adversely affects the length of hospital stay, cost, and cancer recurrence. Anastomotic leakage rates following large bowel resection are reportedly 0.5 to $30 \%$ [14]. Considerable variation is seen between surgeons, but a clinically apparent leakage rate for experienced colorectal surgeons is likely 3.4 to $6 \%$ [2-4]. The identified risk factors for anastomotic leakage are composed of patient factors, which include malnutrition, weight loss, steroid use, smoking, alcohol, American Society of Anesthesiologists score $>3$ points, various concurrent diseases 
such as cardiovascular disease and diverticulitis, and surgical factors, including a low level of anastomosis, an operation time $>2$ hours, intraperitoneal fecal contamination, anastomotic tension, distal intestinal obstruction, and ischemia in the anastomosis [5]. Among these various causes of anastomotic leakage, ischemia around the anastomosis would be considered a strongly affective factor for repair of an anastomotic site [6, 7]. Several chemical agents have been introduced to attenuate ischemic injury to the colon, but their effect has not been promising, and there is a dearth of data regarding leakage prevention $[8,9]$.

Stem-cell-based therapies for the repair and regeneration of various tissues and organs offer a paradigm shift that may provide alternative therapeutic solutions for a number of diseases. Adult stem cells are more readily available, as there are neither ethical nor immunoreactive considerations as long as they are of autologous tissue origin. Tadauchi et al. [10] and Nakagami et al. [11] reported that bone-marrow-derived mononuclear cells (BM-MNCs) enhanced healing of ischemic injury in rats. Much research has focused on mesenchymal stem cells isolated from bone marrow stroma, and cell therapy using BM-MNCs has shown promise for various ischemic diseases. However, bone marrow procurement is extremely painful for patients, and yields of harvested cells are low [12]. Adipose-derived stem cells have the capacity for both direct differentiation into endothelial cells and an indirect effect that involves secretion of angiogenic growth factors [13, 14]. Furthermore, the harvest and extraction of adipose-tissue-derived stem cells (ASCs) is easier and safer than that of BM-MNCs [12]. However, there are few reports on use of ASCs to treat gastrointestinal ischemic disorders. Therefore, we conducted this study to verify the therapeutic effect of ASCs on the healing of ischemic colonic anastomoses.

\section{METHODS}

This animal experiment was approved by the Institutional Animal Review Committee of Inje University prior to beginning the study (approval no. 2010-060).

\section{Preparation of fibrinogen and thrombin solutions}

Fibrinogen and thrombin solutions were prepared for isolation and culture, as well as local implantation, of ASCs. Plasminogenfree fibrinogen, obtained from pooled human plasma (Sigma-Aldrich Co., St. Louis, MO, USA), was dissolved in Dulbecco's modified eagle medium (DMEM; Invitrogen, Carlsbad, CA, USA) containing $100-\mu \mathrm{g} / \mathrm{mL}$ aminomethylbenzoic acid (Sigma-Aldrich Co.) to prepare four fibrinogen working solutions of $5 \mathrm{mg} / \mathrm{mL}$. A thrombin (Sigma-Aldrich Co.) working solution was prepared by dissolving thrombin in DMEM containing $40-\mathrm{mM} \mathrm{CaCl}_{2}$ to a concentration of $1 \mathrm{NIH} \mathrm{U/mL}$.

\section{Isolation and culture of ASCs}

Sprague-Dawley rats (Charles River Laboratories Inc., Seoul, Korea), weighing up to $200 \pm 10 \mathrm{~g}$, were anesthetized with an intravenous injection of ketamine $(10 \mathrm{mg} / \mathrm{kg})$. Rat adipose tissue (AT) was harvested from the suprascapular and inguinal areas. After the fibrous tissue, visible blood vessels, and blood clots had been removed, the AT was washed with Dulbecco's phosphate buffered saline and minced into 2 to $3-\mathrm{mm}^{3}$ fragments. The AT fragments were suspended in the thrombin working solution after washing with DMEM containing $20-\mu \mathrm{g} / \mathrm{mL}$ gentamicin. The suspended AT fragments were mixed with the same volume of $2.5-\mathrm{mg} / \mathrm{mL}$ fibrinogen solution; then, $10 \mathrm{~mL}$ of a mixture containing $3 \mathrm{~g}$ of AT fragments was placed into a $100-\mathrm{mm}$ tissue culture dish. All previous steps were performed on ice. After a 2-hour incubation in a humidified chamber at $37^{\circ} \mathrm{C}$ to ensure complete polymerization, $10 \mathrm{~mL}$ of growth culture medium were added to the tissue culture dish to completely cover the fibrin matrix. Organ culture was performed under dynamic conditions at $15 \mathrm{rpm}$ to facilitate nutrient and gas exchange. The growth culture medium was replenished with fresh medium three times per week.

After 14 days of organ culture, the outgrown cells in the fibrin matrix were recovered by using selective degradation of the fibrin matrix using 5,000 units of urokinase (Sigma-Aldrich Co.) for 30 minutes in the presence of $10 \%$ calf serum in DMEM. The cell number/g of AT was determined by using fluorometric DNA quantification. The recovered cells were plated on tissue culture dishes and propagated using a conventional two-dimensional culture. When cells reached $80 \%$ confluency, they were detached with trypsin-ethylenediaminetetraacetic acid and replated at 2,000 cells $/ \mathrm{cm}^{2}$. This initial passage was referred to as passage 1 .

\section{In vitro mesenchymal differential potential of the isolated ASCs}

Isolated ASCs at passage 3 were used to evaluate the differentiation potential into adipogenic, osteogenic, and endothelial cell lineages. ASCs $\left(5 \times 10^{4}\right.$ cells) were transferred to each well of 24multiwell plates in culture medium. After 5 hours, the ASCs were induced into an adipogenic lineage by culturing the cells for 2 weeks in 0.5-mM 3-isobutyl-1-methylxanthine (Sigma-Aldrich Co.), 1-M dexamethasone (Sigma-Aldrich Co.), 10-M insulin (SigmaAldrich Co.), and 10-vol\% fetal bovine serum (FBS). Differentiation was confirmed by microscopic observation of intracellular lipid droplets using Sudan Black staining.

Osteogenic differentiation was induced by culturing the cells for 2 weeks in DMEM containing 100-M dexamethasone, 50-M ascorbic acid (Sigma-Aldrich Co.), 10-mM glycerol phosphate (SigmaAldrich Co.), and 10-vol\% FBS. Differentiation was examined by extracellular matrix calcification using phase-contrast microscopy. Subcultured outgrown ASCs were seeded on fibrin hydrogel and induced with $20 \mathrm{ng} / \mathrm{mL}$ of vascular endothelial growth factor (VEGF; R\&D Systems, Minneapolis, MN, USA) to differentiate endothelial cells in vitro. Endothelial cell differentiation was confirmed by observing capillary-like network formation and CD31 expression. For the determination of $\mathrm{CD} 31$ expression, ASCs underwent im- 
munofluorescence staining with anti-von Willebrand Factor (vWF) antibody to detect protein expression. Alexa Fluor 488-conjugated antimouse immunoglobulin $\mathrm{G}$ was used for signal detection.

\section{Establishing the ischemic colonic anastomosis model}

Sixty 10-week-old male Sprague-Dawley rats, weighing $370 \pm 50 \mathrm{~g}$, were used. Anesthesia was induced with an intraperitoneal injection of ketamine (35 to $50 \mathrm{mg} / \mathrm{kg}$ ) combined with inhalation of $2 \%$ isoflurane in oxygen. The ischemic colonic anastomosis model was established by modifying Nagahata's method [15]. The colon was cut and divided from the rectovesical pouch at the proximal $3 \mathrm{~cm}$ of the descending colon. Both ends of the divided colon were anastomosed with 6-0 Prolene sutures. Anastomotic ischemia was created by ligating each $2 \mathrm{~cm}$ of the remote marginal vessels from the anastomosis. Blood flow around the anastomosis was measured using laser Doppler flowmetry on the nearest epicolic vessel around the anastomosis. Further ligations of the marginal vessels were made until the blood flow decreased to $<50 \%$ of normal (Fig. 1 ).

\section{Local implantation of ASCs to the ischemic bowel wall}

In each rat in the randomly assigned ASC group, ASCs were locally transplanted directly into the ischemic bowel wall four or five times around the anastomosis using $1 \times 10^{6}$ cells. The ASCs were transplanted with a mixture of fibrinogen and thrombin for stable fixa-

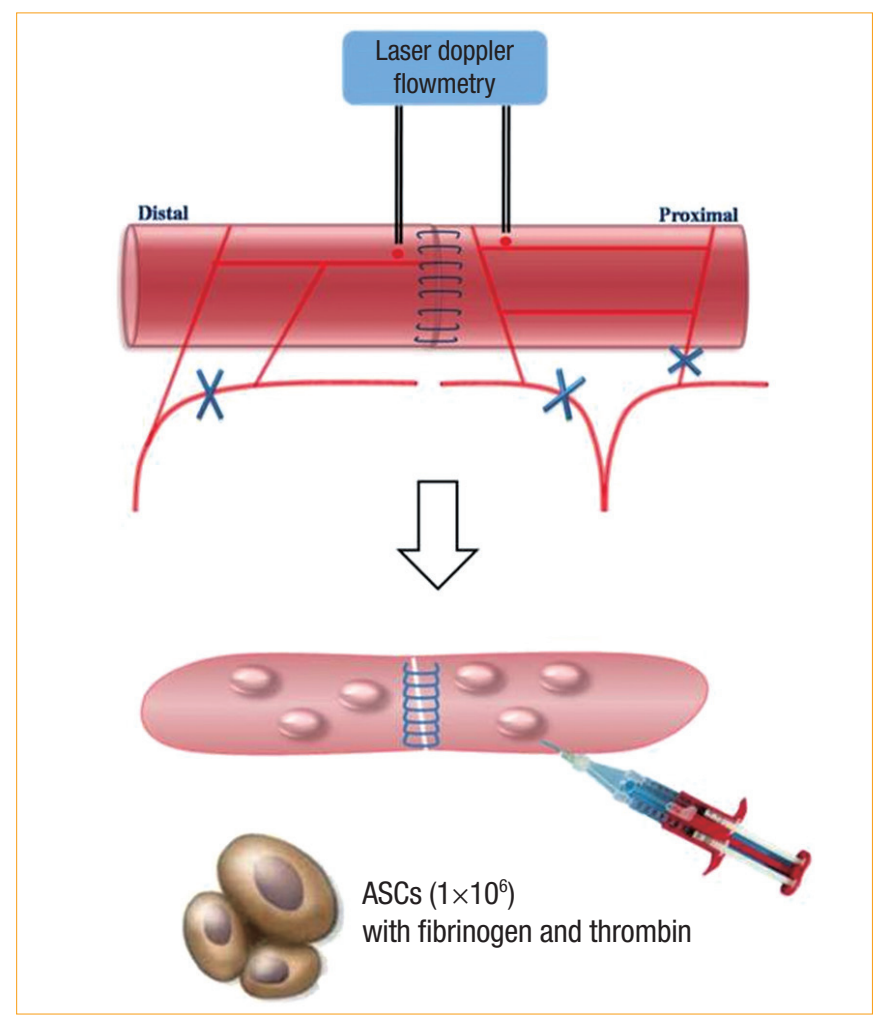

Fig. 1. Scheme for establishing the ischemic colonic anastomosis and transplantation of adipose-tissue-derived stem cells (ASCs). tion to the bowel wall (Fig. 1). No treatment was administered to the control group. The abdominal wound was closed by suturing with 3-0 silk. The rats were fed standard rat chow and provided with tap water postoperatively.

\section{Assessment of recovery from ischemic colonic anastomosis}

The rats were euthanized with $\mathrm{CO}_{2}$ on postoperative day 7 . Healing of the anastomosis was assessed by measuring loss of body weight, wound infection, anastomotic leakage, mortality, adhesion formation, ileus, anastomotic stricture, anastomotic bursting pressure, ischemic ulcer, and histopathological features including microvascular density.

Body weight was measured to evaluate the catabolic and the anabolic states postoperatively. Body weight was measured daily and compared with that preoperatively. Adhesions were evaluated using a scale reported by van der Ham et al. [16]: 0, no adhesion; 1, mild adhesions, mainly between the lesion and omentum; 2 , moderate adhesion, between the lesion and a loop of the small bowel and the omentum; 3 , severe, extensive adhesion, including abscess formation [16]. Ileus was defined as a small intestinal opening near the ileocecal junction dilated $\geq 1.5 \mathrm{~cm}$. Anastomotic stricture was evaluated as follows: none, no preanastomotic colonic dilatation and stool passes freely; mild, solid stool passes, but mild preanastomotic colonic dilatation; moderate, solid stool not passing, but liquid stool passes; severe, no stool passes, but infused fluid passes [17]. The anastomotic bursting pressure was measured with a catheter connected to a barometer (Gamma G7, HEINE, Munich, Germany). The colon $2.5 \mathrm{~cm}$ above and below the anastomosis was cut, and fecal content was cleaned off by gentle washing with saline. The proximal end of the colon was ligated using 3-0 silk sutures, and a catheter was secured in the distal end and connected separately to an infusion pump system through a three-way catheter and barometer. The bowel was infused with a continuous flow of saline mixed with methylene blue $(1.5 \mathrm{~mL} / \mathrm{min})$. The bursting pressure was defined as the pressure at which leakage of saline or gross rupture was noted. Ischemic ulcers were assessed by measuring the number and the sizes of ulcers after measuring the bursting pressure with an opening at the antimesenteric border. The anastomotic site was stained with hematoxylin and eosin to evaluate its histological appearance. The histological grade was determined using the modified criteria of Phillips et al. [18]. Inflammatory cell infiltration, fibroblasts, and collagen deposition were graded from 0 to 4 as follows: 0 , no alteration; 1 , mild alteration; 2 , moderate alteration; 3 , dense alteration; and 4 , profuse alteration. The microvascular density was measured by using capillary immunohistochemistry for CD31 (PECAM-1, Santa Cruz Biotechnology Inc., Santa Cruz, CA, USA) to identify angiogenesis and was scored as microvessel number $/ \mathrm{mm}^{2}$. All data were analyzed with SPSS ver 17.0 (SPSS Inc., Chicago, IL, USA). The Mann-Whitney U-test and the chi-square test were used to compare the groups. A P-value $<0.05$ was considered statistically significant. 


\section{RESULTS}

\section{Identification of differentiation potential}

Cells isolated from AT exhibited similar homogenous fibroblastic morphologies (Fig. 2A). At passage 1, the cells formed colonies composed of multilayered fibroblastic cells. Fibroblastic cell populations proliferated gradually and could be subcultured over nine passages. Cells were differentiated into adipogenic, osteogenic, and endothelial cell lineages by using lineage-specific induction factors to study the multilineage capacity of the ASCs. Differentiation of ASCs into osteoblasts was induced by incubating the cells with low concentrations of ascorbic acid, glycerol phosphate, and dexamethasone for 2 weeks. ASCs formed tightly packed colonies
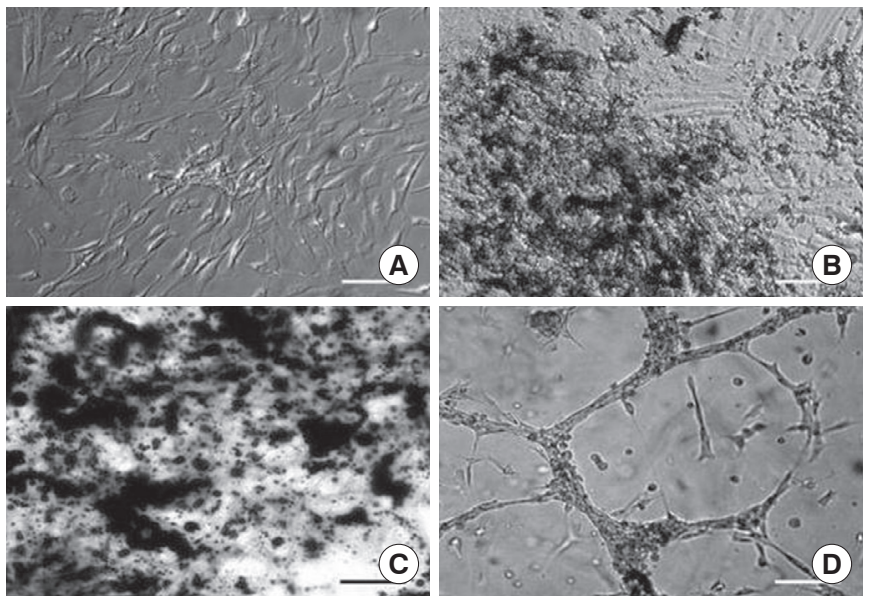

Fig. 2. In vitro biological properties of isolated adipose-tissue-derived stem cells (ASCs). (A) Micrographs of isolated ASCs appear like fibroblasts at passage 1. (B-D) ASCs differentiated into various mesenchymal cells: (B) osteoblasts (phase-contrast micrograph), (C) adipocytes (Sudan black staining), and (D) endothelial cells (phase-contrast micrograph).

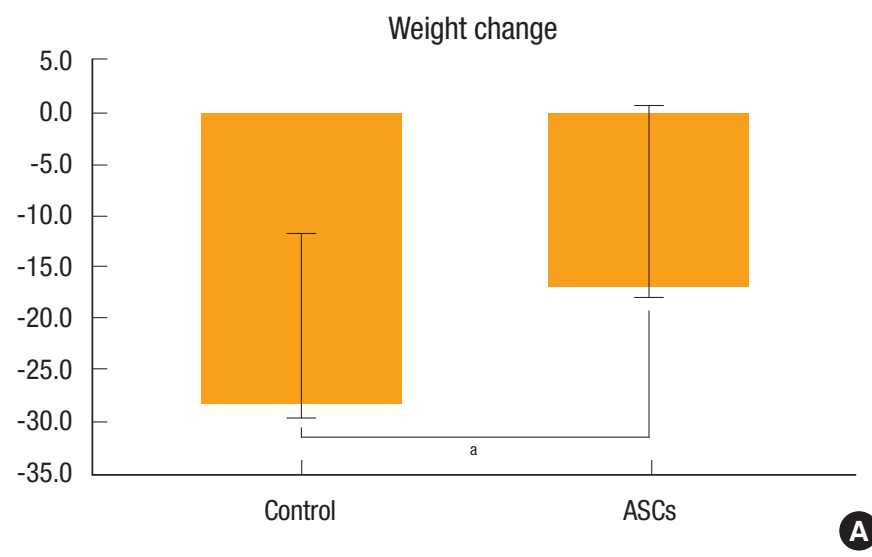

and exhibited dense and granular areas within individual colonies, and calcium deposition was visualized as coarse precipitates (Fig. $2 \mathrm{~B})$. When the cells were cultured in adipogenic differentiation medium for 2 weeks, they showed extensive accumulation of multiple intracytoplasmic droplets, which were stained with the lipophilic dye Sudan Black and were consistent with the preadipocyte phenotype (Fig. 2C). ASCs formed capillary-like networks within 1 day after VEGF stimulation and expressed vWF upon immunofluorescence staining, indicating that the cells retained their ability to differentiate into endothelial cells (Figs. 2D and 3).

\section{Outcome measures}

Overall body weights decreased postoperatively, but the weight

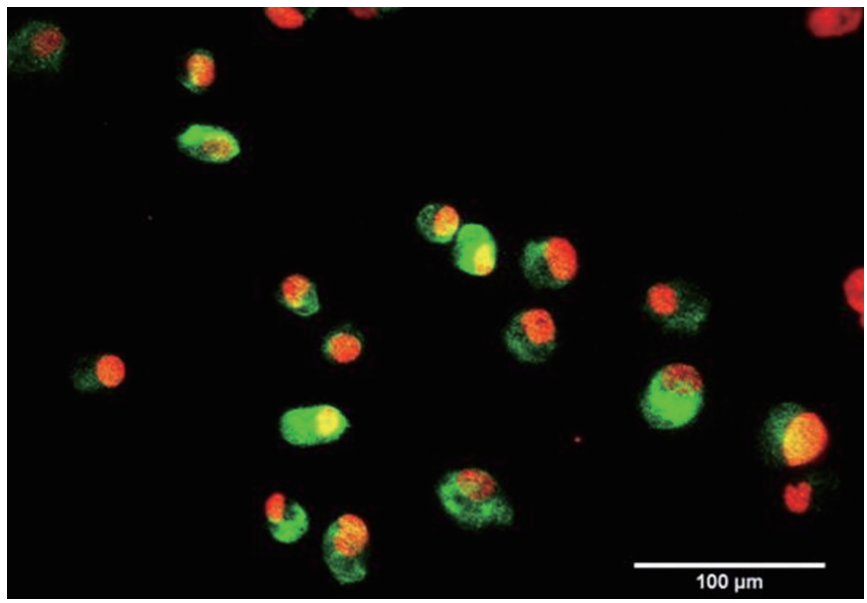

Fig. 3. Immunofluorescence staining of adipose-tissue-derived stem cells (ASCs) using anti-von Willebrand Factor (vWF) antibody. ASCs expressed vWF on immunofluorescence staining (green signal) after vascular endothelial growth factor stimulation, indicating that the cells retained their ability to differentiate into endothelial cells.

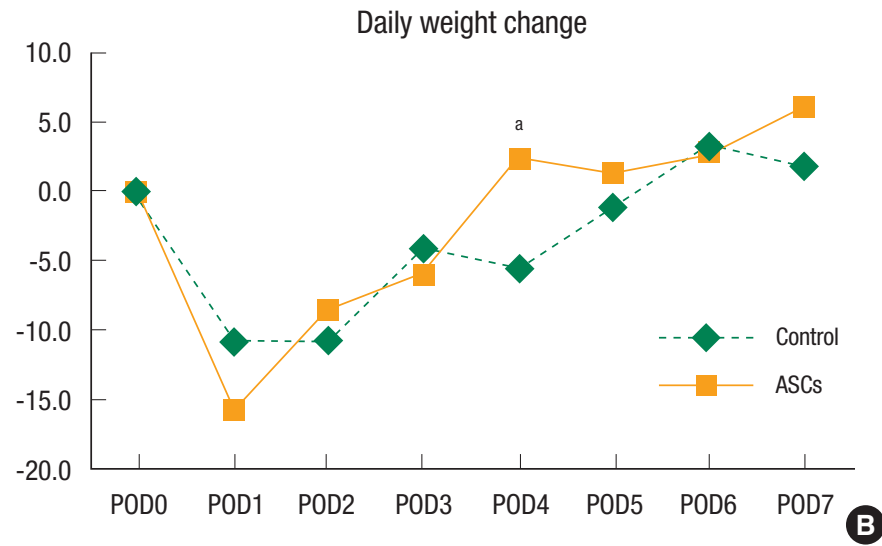

Fig. 4. (A) Less overall weight loss was observed in the adipose-tissue-derived stem cell (ASC) group than in the control group. (B) Daily change in weight in the ASC group was significantly higher than that in the control group on postoperative day (POD) 4 . ${ }^{\mathrm{a} P}<0.01$. 
Table 1. Outcome measures

\begin{tabular}{lccc}
\hline & Control & ASCs & P-value $^{\text {a }}$ \\
\hline Wound infection & $2 / 27$ & $0 / 26$ & NS \\
Ileus & $4 / 27$ & $0 / 26$ & 0.041 \\
Anastomotic leakage & $4 / 30$ & $4 / 30$ & NS \\
Mortality & $3 / 30$ & $4 / 30$ & NS
\end{tabular}

Values are represented as the number of rats.

ASCs, adipose-tissue-derived stem cells; NS, not significant.

${ }^{a}$ Chi-square test.

Table 2. Macroscopic findings

\begin{tabular}{lccc}
\hline & Control & ASCs & P-value \\
\hline Adhesion & $2.85(0.36)$ & $2.50(0.65)$ & NS \\
Stricture & $1.41(1.25)$ & $0.88(1.21)$ & 0.018 \\
Ulcer number & $1.11(1.09)$ & $0.58(0.64)$ & 0.035 \\
Ulcer size & $11.69(12.35)$ & $11.15(13.59)$ & NS \\
\hline
\end{tabular}

Values are presented as mean (standard deviation).

ASCs, adipose-tissue-derived stem cells; NS, not significant.

Table 3. Microscopic findings

\begin{tabular}{lccc}
\hline & Control & ASCs & P-value \\
\hline Inflammation & $2.88(1.11)$ & $1.50(0.51)$ & 0.000 \\
Fibroblast & $2.88(1.05)$ & $3.67(0.49)$ & 0.029 \\
Collagen & $0.35(0.49)$ & $0.76(0.44)$ & 0.041 \\
MVD (number $\left./ \mathrm{mm}^{2}\right)$ & $25.79(9.44)$ & $32.64(8.88)$ & 0.032 \\
\hline
\end{tabular}

Values are presented as mean (standard deviation).

MVD, microvascular density; ASCs, adipose-tissue-derived stem cells.

loss in the ASC group was significantly less than that in the control group (Fig. 4A). A comparison of daily change in body weight showed a significantly higher increase on postoperative day 4 and earlier recovery of weight in the ACS group than in the control group (Fig. 4B). Wound infection, anastomotic leakage, and mortality were not significantly different between the two groups, but ileus occurred significantly less frequently in the ASC group than in the control group $(\mathrm{P}<0.05)$ (Table 1). Bursting pressure was significantly higher in the ASC group than in the control group $(153.92 \pm 46.13 \mathrm{mmHg}$ vs. $121.31 \pm 35.99 \mathrm{mmHg}, \mathrm{P}<0.01)$ (Fig. 5). Adhesion and ulcer size in the two groups were not different, but there were significantly fewer strictures and ulcers in the ASC group than in the control group $(\mathrm{P}<0.05)$ (Table 2). The microscopic findings revealed that inflammation was significantly less frequent in the ASC group than in the control group $(\mathrm{P}<0.01)$ (Table 3, Fig. 6). However, collagen deposition, as shown by Masson trichrome staining, was significantly more prevalent in the ASC group than in the control group $(\mathrm{P}<0.05)$. Microvascular density was significantly higher in the ASC group than in the control group $(\mathrm{P}<0.05)$ (Table 3, Fig. 7).

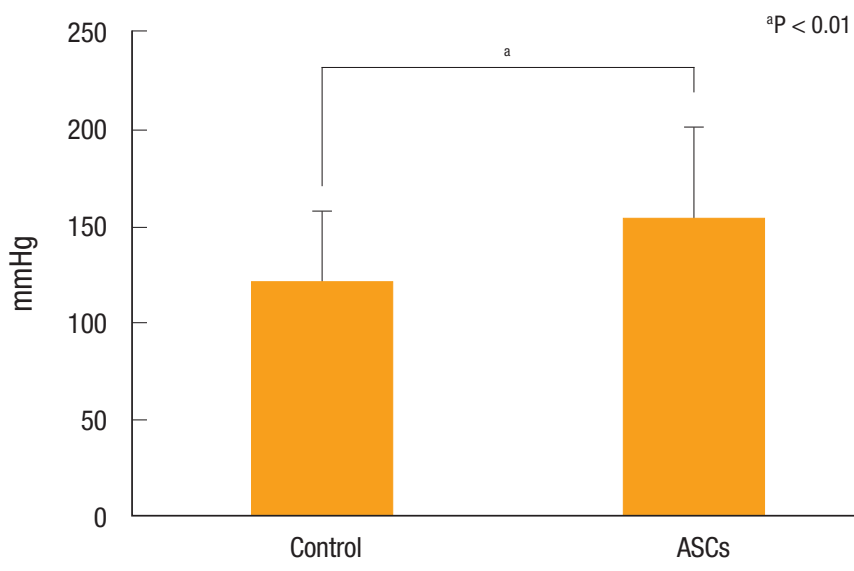

Fig. 5. Bursting pressure. adipose-tissue-derived stem cells (ASCs).

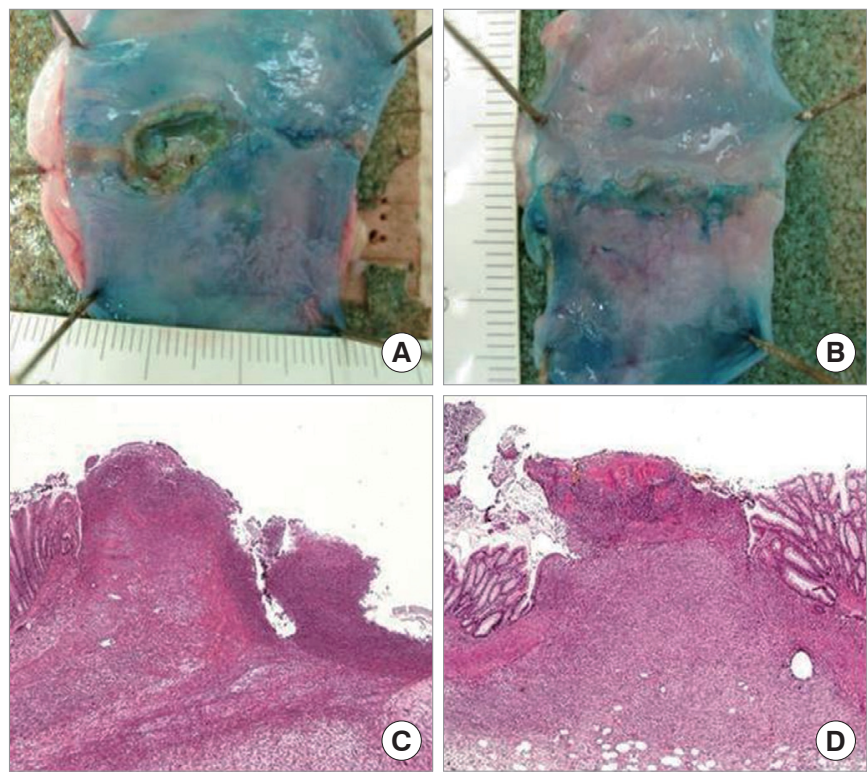

Fig. 6. Macroscopic and microscopic findings of anastomotic area (A and C, control group; B and D, adipose-tissue-derived stem cell [ASC] group). (A) A large and deep ulcer is seen in the control group. (B) Small and shallow ulcers are seen in the ASC group. (C) A deep ulcer defect with acute inflammation throughout the wall is seen in the control group (H\&E, $\times 40)$. (D) The anastomotic site is filled with fibrous tissue with a few exudates on the surface in the ASC group $(\mathrm{H} \& \mathrm{E}, \times 40)$.

\section{DISCUSSION}

The basic principles for preventing an anastomotic leakage consist of an adequate blood supply, no tension, and inverted mucosal suturing [5]. Recently, the soluble intraluminal prosthesis (SBS-tube), the coloshield, and other buttressing materials have been developed to prevent anastomotic dehiscence by reinforcing the anastomosis. However, no studies have shown a clear benefit of these adjuncts, and complications such as erosion of the tube through 
Volume 28, Number 3, 2012

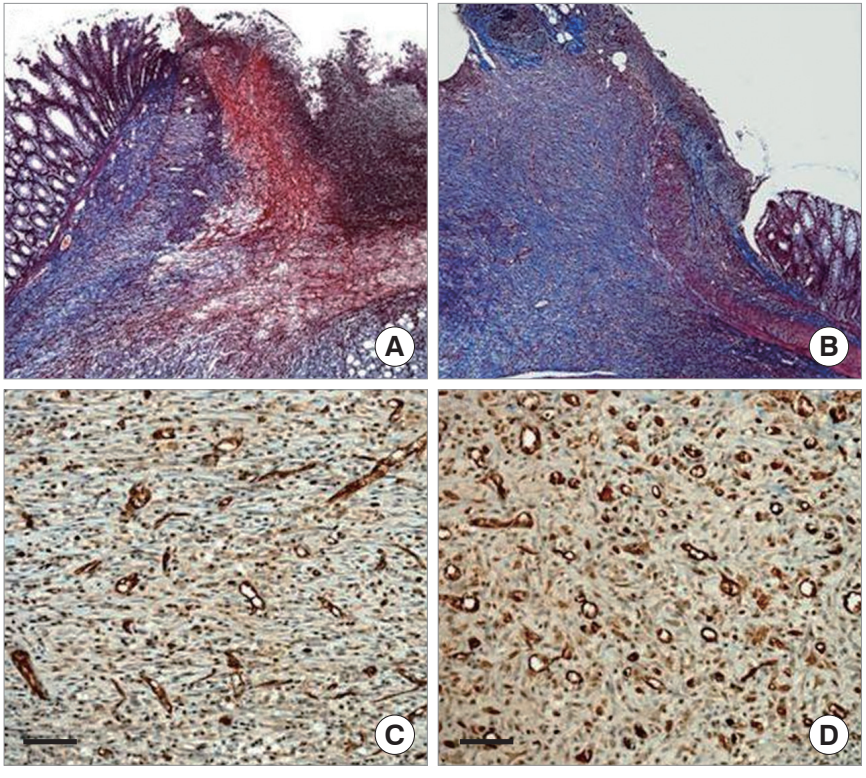

Fig. 7. Special staining for comparison (A and B, Masson trichrome staining, $\times 40$; $C$ and $D$, immunohistochemistry for CD31, $\times 200$; the scale bar is $200 \mu \mathrm{m}$ ). (A) Scanty collagen deposition is shown in the anastomotic area of the control group. (B) Dense collagen deposition with fibrosis is noted in the adipose-tissue-derived stem cell (ASC) group. (C) Slight neovascularization is shown in the control group. (D) A markedly increased neovascularization is shown in the ASC group.

the colon and obstruction have been reported [19]. Fibrin glue and a bovine pericardial strip for buttressing the staple line are predicted to be helpful for an anastomosis [20]. However, little evidence supports their widespread use. Numerous investigations have focused on the reinforcement of a stapled or sutured anastomosis despite the fact that prevention of ischemia is one of the most important principles for a safe anastomosis. Nevertheless, there are few studies about promoting angiogenesis around an ischemic anastomosis.

Stem cell research has received much attention in recent years and has shown a beneficial effect in various ischemic diseases [10, 21, 22]. Many studies have focused on mesenchymal stem cells isolated from bone marrow stroma. However, ASCs also have the capacity for both direct differentiation into endothelial cells and an indirect effect that involves secretion of angiogenic growth factors $[13,14]$. Furthermore, the harvest and the extraction of ASCs are easier and safer than those of BM-MNCs [12]. However, no reports on the use of ASCs to treat ischemic colonic anastomosis are available. Therefore, we intended to confirm the effect of ASCs, which are abundant in AT and are easily and safely extracted, on facilitating healing of an ischemic-colonic-risk anastomosis.

In the present study, ASCs extracted from the subcutaneous fat tissue in rats were identified as mesenchymal stem cells and were cultured and differentiated as AT, bone tissue, and endothelial cells. In particular, ASCs expressed vWF (green signal) after VEGF stim- ulation, indicating that the cells retained their ability to differentiate into endothelial cells. This mesenchymal differentiation result was similar to that of Gimble and Guilak [23]. Our animal model of ischemic colonic anastomosis was developed by modifying the ischemic colitis model from Nagahata et al. [15]. The method of ligating each marginal vessel $2-\mathrm{cm}$ remote from the anastomosis is similar to that of Adas et al. [24], who recently developed an ischemic colonic anastomosis model in rats. However, only ligating the length of marginal vessels was not a guarantee of reproducible and steady ischemic conditions of a colonic anastomosis and could cause a selection bias. According to a study by Seike et al. [25], anastomotic complications such as leakage and stenosis occur at a much higher rate in patients who demonstrate $>50 \%$ blood flow reduction on laser Doppler flowmetry after inferior mesenteric artery clamping during an anterior resection. Thus, we used laser Doppler flowmetry to determine the exact flow rate after ligating each marginal vessels to create an ischemic condition of $<50 \%$ normal blood flow.

In the present study, the ASC group had less of a change in body weight postoperatively and had a quicker recovery to normal body weight than did the control group. The catabolic rate after a major operation is well-known to be increased, resulting in a loss of lean body mass, which consequently causes a reduction in body weight [26]. Thus, the reduced loss and the more rapid recovery of body weight after the operation is believed to indicate a lower catabolic rate and enhanced recovery in the ASC-treated group. Ileus, inflammation, ulcers, and stricture were seen less often in the ASC group than in the control group. The common clinicopathological features of an ischemic injured colon are ileus, inflammation, and stricture of the affected bowel [27]. However, the ASC group did not have such severe injuries. Thus, the ASCs are thought to have attenuated the ischemic injury and/or enhanced the recovery of the ischemic colonic anastomosis. A report by Tadauchi et al., who studied recovery from ischemic bowel injury by using BM-MNCs, found that transplanted BM-MNCs administered into the ischemic colonic wall enhanced the recovery of the nerve plexus in an injured colon and subsequently reduced the colonic transit time [10]. The less frequent ileus in the ASC group might be explained by a similar BM-MNC mechanism, but additional studies are needed. The bursting pressure is the one of the most important measurements for anastomotic healing in the intestine and depends mainly on the collagen density. The ASC group in this study had a higher bursting pressure and a greater collagen density than the control group did. This result showed that ASCs enhanced wound healing of an ischemic colonic anastomosis. ASCs have the capacity for both direct differentiation into endothelial cells and an indirect effect that involves secretion of angiogenic growth factors $[13,14]$. The microvascular density is a well-known method of measuring angiogenesis, which is critical for wound healing $[10,24]$. We measured the microvascular density by using immunohistochemical staining with the antiCD 31 antibody, and higher intensity staining was found in the ASC group than in the control 
group. However, a limitation of the present study was that the visible mechanism of angiogenesis induced by ASCs, including cell differentiation in vivo and the presence of angiogenic factors such as VEGF and stromal-derived factor, was not shown directly, but recent studies regarding cell therapy and ischemic injury to the colon do not show the exact mechanism of in vivo differentiation. Adas et al. [24] showed that mesenchymal stem cells were detected in the ischemic colonic wall, but no data regarding differentiation in vivo or the presence of angiogenic factors were provided. Tadauchi et al. [10], who studied the therapeutic effect of BM-MNCs in ischemic colitis, showed that transplanted cells were detected in all layers, i.e., mucosa, submucosa, muscularis propria, and subserosa. However, none of the transplanted cells were positive for $\alpha$ smooth muscle actin, a marker of smooth muscle cells. Furthermore, none of the cells were double-positive for PKH26, vWF, or PGP9.5, markers of endothelial cells and neural cells, respectively. These results suggest that BM-MNCs only rarely differentiate into smooth muscle cells, endothelial cells, or neural cells. Therefore, subsequent studies should include the exact mechanism of enhanced angiogenesis by using cell tracking and measurement of angiogenic factors.

In conclusion, locally-transplanted ASCs, which were easily extracted from subcutaneous fat tissue, attenuated ischemic injury of a colonic anastomosis and enhanced anastomotic healing by promoting angiogenesis. ASCs could, thus, be a novel strategy for accelerating healing of a colonic ischemic risk anastomosis.

\section{CONFLICT OF INTEREST}

No potential conflict of interest relevant to this article was reported.

\section{ACKNOWLEDGMENTS}

This work was supported by a Boryung Colon Cancer Research Foundation of the Korean Society of Coloproctology grant.

\section{REFERENCES}

1. Fielding LP, Stewart-Brown S, Blesovsky L, Kearney G. Anastomotic integrity after operations for large-bowel cancer: a multicentre study. Br Med J 1980;281:411-4.

2. Golub R, Golub RW, Cantu R Jr, Stein HD. A multivariate analysis of factors contributing to leakage of intestinal anastomoses. J Am Coll Surg 1997;184:364-72.

3. Alves A, Panis Y, Trancart D, Regimbeau JM, Pocard M, Valleur P. Factors associated with clinically significant anastomotic leakage after large bowel resection: multivariate analysis of 707 patients. World J Surg 2002;26:499-502.

4. Peeters KC, Tollenaar RA, Marijnen CA, Klein Kranenbarg E, Steup WH, Wiggers T, et al. Risk factors for anastomotic failure after total mesorectal excision of rectal cancer. Br J Surg 2005; 92:211-6.
5. Kingham TP, Pachter HL. Colonic anastomotic leak: risk factors, diagnosis, and treatment. J Am Coll Surg 2009;208:269-78.

6. Posma LA, Bleichrodt RP, van Goor H, Hendriks T. Transient profound mesenteric ischemia strongly affects the strength of intestinal anastomoses in the rat. Dis Colon Rectum 2007;50:1070-9.

7. Posma LA, Bleichrodt RP, Lomme RM, de Man BM, van Goor H, Hendriks T. Early anastomotic repair in the rat intestine is affected by transient preoperative mesenteric ischemia. J Gastrointest Surg 2009;13:1099-106.

8. Irkorucu O, Ucan BH, Cakmak GK, Emre AU, Tascilar O, Ofluoglu E, et al. Does sildenafil reverse the adverse effects of ischemia on ischemic colon anastomosis: yes, 'no'. Int J Surg 2009;7:39-43.

9. Karatepe O, Kurtulus I, Yalcin O, Battal M, Kamali G, Aydin T. Adrenomedulline improves ischemic left colonic anastomotic healing in an experimental rodent model. Clinics (Sao Paulo) 2011; 66:1805-10.

10. Tadauchi A, Narita Y, Kagami H, Niwa Y, Ueda M, Goto H. Novel cell-based therapeutic strategy for ischemic colitis with use of bone marrow-derived mononuclear cells in rats. Dis Colon Rectum 2009;52:1443-51.

11. Nakagami H, Maeda K, Morishita R, Iguchi S, Nishikawa T, Takami Y, et al. Novel autologous cell therapy in ischemic limb disease through growth factor secretion by cultured adipose tissue-derived stromal cells. Arterioscler Thromb Vasc Biol 2005;25:2542-7.

12. Mizuno H. Adipose-derived stem cells for tissue repair and regeneration: ten years of research and a literature review. J Nihon Med Sch 2009;76:56-66.

13. Zeng Q, Li X, Beck G, Balian G, Shen FH. Growth and differentiation factor-5 (GDF-5) stimulates osteogenic differentiation and increases vascular endothelial growth factor (VEGF) levels in fatderived stromal cells in vitro. Bone 2007;40:374-81.

14. Cao Y, Sun Z, Liao L, Meng Y, Han Q, Zhao RC. Human adipose tissue-derived stem cells differentiate into endothelial cells in vitro and improve postnatal neovascularization in vivo. Biochem Biophys Res Commun 2005;332:370-9.

15. Nagahata Y, Azumi Y, Akimoto T, Nomura H, Ichihara T, Idei H, et al. Role of platelet activating factor on severity of ischemic colitis. Dis Colon Rectum 1999;42:218-24.

16. van der Ham AC, Kort WJ, Weijma IM, van den Ingh HF, Jeekel J. Effect of fibrin sealant on the healing colonic anastomosis in the rat. Br J Surg 1991;78:49-53.

17. Bae KB, Kim SH, Jung SJ, Hong KH. Cyanoacrylate for colonic anastomosis; is it safe? Int J Colorectal Dis 2010;25:601-6.

18. Phillips JD, Kim CS, Fonkalsrud EW, Zeng H, Dindar H. Effects of chronic corticosteroids and vitamin A on the healing of intestinal anastomoses. Am J Surg 1992;163:71-7.

19. Yo LS, Consten EC, Quarles van Ufford HM, Gooszen HG, Gagner M. Buttressing of the staple line in gastrointestinal anastomoses: overview of new technology designed to reduce perioperative complications. Dig Surg 2006;23:283-91.

20. Nguyen NT, Nguyen CT, Stevens CM, Steward E, Paya M. The efficacy of fibrin sealant in prevention of anastomotic leak after 
laparoscopic gastric bypass. J Surg Res 2004;122:218-24.

21. Tateishi-Yuyama E, Matsubara H, Murohara T, Ikeda U, Shintani $\mathrm{S}$, Masaki $\mathrm{H}$, et al. Therapeutic angiogenesis for patients with limb ischaemia by autologous transplantation of bone-marrow cells: a pilot study and a randomised controlled trial. Lancet 2002;360: 427-35.

22. Kondo K, Shintani S, Shibata R, Murakami H, Murakami R, Imaizumi M, et al. Implantation of adipose-derived regenerative cells enhances ischemia-induced angiogenesis. Arterioscler Thromb Vasc Biol 2009;29:61-6.

23. Gimble J, Guilak F. Adipose-derived adult stem cells: isolation, characterization, and differentiation potential. Cytotherapy 2003; 5:362-9.
24. Adas G, Arikan S, Karatepe O, Kemik O, Ayhan S, Karaoz E, et al. Mesenchymal stem cells improve the healing of ischemic colonic anastomoses (experimental study). Langenbecks Arch Surg 2011; 396:115-26.

25. Seike K, Koda K, Saito N, Oda K, Kosugi C, Shimizu K, et al. Laser Doppler assessment of the influence of division at the root of the inferior mesenteric artery on anastomotic blood flow in rectosigmoid cancer surgery. Int J Colorectal Dis 2007;22:689-97.

26. Ryan NT. Metabolic adaptations for energy production during trauma and sepsis. Surg Clin North Am 1976;56:1073-90.

27. Theodoropoulou A, Koutroubakis IE. Ischemic colitis: clinical practice in diagnosis and treatment. World J Gastroenterol 2008; 14:7302-8. 